\title{
Surgical flow disturbances in dedicated minimally invasive surgery suites: an observational study to assess its supposed superiority over conventional suites
}

\author{
Mathijs D. Blikkendaal $^{1}$ - Sara R. C. Driessen ${ }^{1} \cdot$ Sharon P. Rodrigues $^{1}$ • \\ Johann P. T. Rhemrev ${ }^{3} \cdot$ Maddy J. G. H. Smeets ${ }^{3} \cdot$ Jenny Dankelman $^{2} \cdot$ \\ John J. van den Dobbelsteen ${ }^{2} \cdot$ Frank Willem Jansen $^{1,2}$
}

Received: 14 December 2015/ Accepted: 3 May 2016/Published online: 20 May 2016

(c) The Author(s) 2016. This article is published with open access at Springerlink.com

\begin{abstract}
Background Minimally invasive surgery (MIS) is frequently compromised by surgical flow disturbances due to technology- and equipment-related failures. Compared with MIS in a conventional cart-based OR, performing MIS in a dedicated integrated operating room (OR) is supposed to be beneficial to patient safety. The aim of this study was to compare a conventional OR with an integrated OR with regard to the incidence and effect of equipmentrelated surgical flow disturbances during an advanced laparoscopic gynecological procedure [laparoscopic hysterectomy (LH)].

Methods Using video recording, $40 \mathrm{LHs}$ performed between November 2010 and April 2012 (20 in a conventional cart-based $\mathrm{OR}$ and 20 in an integrated $\mathrm{OR}$ ) were analyzed by two different observers. Outcome measures were the number, duration and effect (on a seven-point ordinal scale) of the surgical flow disturbances (e.g., malfunctioning, intraoperative repositioning, setup device).

Results A total of $103 \mathrm{~h}$ and 45 min was observed. The interobserver agreement was high (kappa $.85, p<.001$ ). Procedure time was not significantly different (NS) [conventional $\mathrm{OR}$ vs. integrated $\mathrm{OR}$, minutes \pm standard deviation (SD), mean $161 \pm 27$ vs. $150 \pm 34$ ]. A total of
\end{abstract}

Frank Willem Jansen

f.w.jansen@lumc.nl

1 Department of Gynecology, Leiden University Medical Center, PO Box 9600, 2300 RC Leiden, The Netherlands

2 Department of BioMechanical Engineering, Technical University Delft, Mekelweg 2, 2628 CD Delft, The Netherlands

3 Department of Gynecology, Bronovo Hospital, PO Box 96900, 2509 JH The Hague, The Netherlands
1651 surgical flow disturbances were observed (mean \pm SD per procedure $40.8 \pm 19.4$ vs. $41.8 \pm 15.9$, NS). The mean number of surgical flow disturbances per procedure with regard to equipment was $6.3 \pm 3.7$ versus $8.5 \pm 4.0$, NS. No clinically relevant differences in the mean effect of these disturbances on the surgical flow between the two OR setups were observed.

Conclusions Performing LH in an integrated OR did not reduce the number of surgical flow disturbances nor the effect of these disturbances. Furthermore, in the integrated $\mathrm{OR}$, repositioning of the monitors was a frequent and timeconsuming source of disturbance. In order to maintain the high standard of surgical safety, the entire surgical team has to be aware that by performing surgery in an integrated OR different potential source for disruption arise.

Keywords Integrated operating room - Minimally invasive surgery $\cdot$ Technical equipment $\cdot$ Surgical flow disturbances · Video observation · Patient safety

In the era of rapidly evolving surgical techniques and technology, the patient, hospital, health insurance and government demand transparency in surgical outcomes and desire the highest degree of patient safety. Merely a decade ago, we started to accept the idea that surgical outcome is affected by more than the patient characteristics and skills of the surgeon alone [1]. In fact, the combination of patient risk factors, task complexity, individual surgical factors, and above all team functioning, operative events and operative environment are responsible for the outcome [13]. Especially in minimally invasive surgery (MIS), patient safety has to rely on a smooth course of the procedure and is depending on proper functioning of the equipment and the working environment [4]. Secondly, compared with 
open surgery, MIS is more prone to disruptions due to problems with the extensive amount of equipment it relies on (either presence, position or functioning) [4-8]. A systematic review revealed that on average per procedure three equipment-/technology-related errors occur. This resembles $23.5 \%$ of the errors in the OR [9]. Additionally, they found that procedures that are more dependent on technology and/or equipment tended to show approximately three times higher equipment-related error rates [9]. Furthermore, during laparoscopic surgery, $47 \%$ of the communication is equipment related, compared with $39 \%$ during open surgery [10].

In order to guarantee an optimal working environment to perform MIS, the industry offers fully integrated surgical suites (e.g., ENDOALPHA by Olympus; iSuite by Stryker; OR $1^{\text {TM }}$ by Karl Storz). They state that-by their optimized design - these are the solution for efficient and safe surgical care by reducing operating room (OR) clutter and staff workload, increasing comfort and enhancing ergonomics and OR team performance [11-14]. Importantly, these statements are only describing potential benefits that are inherently biased by their manufactures and that are not based on objective research [12, 13, 15]. Regarding efficiency, only a couple of studies observed a small amount of time saving (i.e., $\pm 4 \mathrm{~min}$ for setup and $\pm 3 \mathrm{~min}$ for put away [13], $\pm 6 \mathrm{~min}$ in 'preanesthesia time' [16] and 'potentially' $\pm 6 \mathrm{~min}$ in overall OR time [11], respectively). Furthermore, a survey was performed under OR staff to investigate potential benefits of the integrated OR after 2 years of use. The results of the questionnaire showed a preference for the integrated OR; however, problems with staff education, integration and reliability were noted [17]. Another study explored the staff perceptions of the effects of an integrated OR on teamwork. The subjectively measured results of the nurses, consultants and trainees showed greater efficiency, better teamwork and reduced stress levels and therefore a strong preference for working in an integrated OR [18]. Although it is not clear whether an integrated OR is an useful, (cost-)effective and safe solution, globally many hospitals have invested or are investing in one or more integrated surgical suites [11, 17].

One could argue that an integrated OR facilitates such an improvement that patient safety is guaranteed and no extensive research is needed before applying this-expensive-technology [19]. However, it is well established that the failure of integrated devices also can lead to unforeseen problems, and from aviation technology, we know that even the smallest incidents can have catastrophic consequences [8, 20, 21]. One of the most striking examples is the crash of an airplane that, after a missed approach because of suspected gear nose malfunction, descended unnoticed because the entire flight crew became engrossed in the malfunction. Investigation revealed that only the nose landing gear position indicating system (i.e., the light bulb) was broken.

Therefore, quantitative research comparing equipmentrelated error rates in MIS performed in a conventional versus an integrated OR is desired. Studies describing surgical processes were generally based on live observation in the OR; video observation has only been used infrequently [6, 8, 22, 23]. Nevertheless, video registration is deemed superior since it is not limited by the capacity of an observer, cause-and-effect relationships are better analyzable, and the Hawthorne effect (i.e., the awareness of being observed alters the way a person behaves) is minimized [6, 7, 24, 25].

The aim of this prospective observational study was to compare a conventional OR with an integrated OR with regard to the incidence and effect of equipment-/instrument-related surgical flow disturbances during an advanced laparoscopic gynecological procedure (i.e., the laparoscopic hysterectomy (LH)).

\section{Materials and methods}

In a university-affiliated teaching hospital (Bronovo Hospital, The Hague), a prospective registration study was set up to record and analyze surgical flow disturbances during the same procedure in two different OR settings. The LH was chosen as procedure under research, because it is an advanced laparoscopic procedure, performed by a dedicated operating team and requiring a wide array of endoscopic instruments and equipment. The study started in November 2010 and all consecutive LHs that were performed in the conventional (cart-based) OR were registered until the start of the construction of the new integrated OR (Karl Storz OR1 ${ }^{\mathrm{TM}}$ integrated OR system, September 2011). After construction of the integrated OR (October 2011), the same amount of eligible procedures were registered in this setting. Based on a power calculation, we needed 16 procedures in each OR (average $8 \pm 3$ equipment-/instrument-related surgical flow disturbances per procedure and a reduction to 5 regarded to be achievable by the introduction of the integrated OR (power $80 \%$, type I error .05) [25]). The study design did not permit us to exactly determine the number of procedures beforehand, and furthermore, analysis of additional procedures would take an excessive amount of time. Therefore, it was strived for to acquire at least 15 and a maximum of 20 eligible procedures. All procedures were performed by one out of two gynecologists with more than 10 years of experience in advanced gynecologic laparoscopy and were assisted by a person who conducted a fellowship in MIS; a group of five alternated in the position of either circulating or scrub nurse. To become acquainted with the integrated OR 
setting, the entire operating team received multiple training sessions that were provided by the vendor.

In the conventional OR, all standard laparoscopic equipment (insufflator, light source and camera control unit, all manufactured by Karl Storz) was placed on a cart with one flat-screen high-definition monitor on top and one on a swivel arm. The electrosurgical equipment was placed on separate cart(s). In the integrated OR, the standard laparoscopic and electrosurgical equipment (manufacturers identical to conventional OR) was placed on a ceilingmounted boom arm and three flat-screen high-definition monitors (of which one touch screen) were attached to separate ceiling-mounted boom arms.

To minimize the impact on the environment under study, the study was performed with video observation. The researcher (M.D.B.) was present in the OR at the start of each registration, but did not participate in the procedure. All procedures were recorded on a personal computer using a quad-audiovisual recording system that synchronously recorded the input from three video signals and four audio signals (MPEG Recorder 2.1, Noldus Information Technologies, Wageningen, The Netherlands). The video signals captured the endoscopic image and the image from two dome cameras that provided a room overview from different angles (one placed in a corner and one opposite in the middle of the long side of the operating room) (see Fig. 1). The audio signals were captured from two microphones placed on the ceiling next to the dome cameras and two wireless microphones placed on the surgical masks of the surgeon and scrub nurse, respectively. The recordings were started just before the time-out procedure and stopped after the skin of all port sites was sutured. In case technical problems related to the recording equipment were encountered, the procedure was excluded.

The study was approved by the Executive Board of the Bronovo Hospital. The recordings were only to be used for purpose of present study. Prior to the start of the study, all

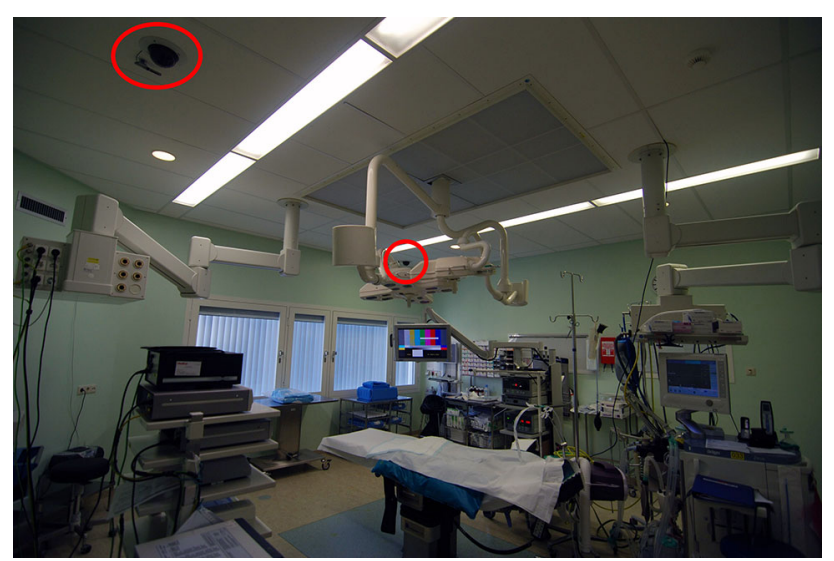

Fig. 1 Conventional cart-based OR (dome cameras are circled)
OR personnel was collectively informed about the study. They were told that the observations were performed to investigate the logistics of equipment and personnel during LH. From each patient, informed consent was obtained.

According to the methodology to analyze a peroperative surgical process described by Den Boer et al., all (potential) surgical steps that are commonly undertaken during LH were defined (Table 1) [26, 27]. The recordings were analyzed with The Observer ${ }^{\circledR}$ XT 11.5 software (Noldus Information Technologies, Wageningen, The Netherlands). Two residents in Obstetrics and Gynecology (M.D.B. and S.R.C.D.) observed the recordings. A random sample of six recordings was scored by both observers. The findings of the two observers for these six procedures were compared, and the interobserver agreement was calculated (function incorporated in The Observer ${ }^{\circledR}$ XT 11.5 software). If satisfactory interobserver agreement would be achieved, the remaining procedures could be annotated by the two observers separately (randomly allocated and analyzed in a non-chronological random order) [5, 23].

\section{Annotation and statistics}

From each procedure, the predefined surgical steps and the presence and effect of predefined surgical flow disturbances were annotated (Table 1). Surgical flow disturbances were defined as stimuli (potentially) distracting one or more members of the sterile team (Table 2). To assess the (potential) severity, the effect on the sterile team members caused by each observed surgical flow disturbance was graded according to a seven-point ordinal scale modified by Persoon et al. (originally described by Healey et al.) (Table 3) [25, 28]. This scale ranges from ' 1 ' as a potentially distracting stimulus to ' 7 ' when the sterile team's work is completely interrupted. Primary outcome measures were the number of surgical flow disturbances per procedure. Secondary, a qualitative assessment was made comparing the types, effect and duration of these surgical flow disturbances for the two different OR settings.

Patient and procedure characteristics were derived by chart review. For statistical analysis, The Observer ${ }^{\circledR}$ XT 11.5 software and SPSS 20.0 statistical software (Chicago, IL, USA) were used. A Pearson Chi-square test was used to compare proportions, and a Student's $t$ test was used for continuous variables. To describe non-normally distributed data (kurtosis between -1 and +2 ) or in case Levene's test showed no homogeneity of variance, the median and interquartile range (IQR, 25th and 75th percentiles) were used and a Mann-Whitney test was performed. A $p<.05$ was considered statistically significant. 
Table 1 Surgical phases and (potential) surgical steps commonly undertaken during laparoscopic hysterectomy (adjusted from Den Boer et al. [26])

\begin{tabular}{ll}
\hline Surgical phases & Surgical steps \\
\hline
\end{tabular}

1. Preoperative

1.1. OR ready (clean, air quality, pressure)

1.2. Instruments and devices present and functioning

1.3. Patient to OR

1.4. Patient on OR table

1.5. Time-out procedure

1.6. Position patient on OR table

1.7. Team scrubs in washing room

1.8. Sterile preparation of instruments

2. Anesthesia and surgical preparation

2.1. Anesthesia and intubation

2.2. Sterilization operating area

2.3. Draping the patient

2.4. Insert urine catheter

2.5. Insert mobilizer in uterus

2.6. Install instruments

3. Procedure

3.1. Create $\mathrm{CO} 2$ pneumoperitoneum

3.2. Insert access ports

3.3. Preparation operative area

3.4. Expose uterine arteries

3.5. Transect uterine arteries

3.6. Separate uterus from vagina

3.7. Specimen retrieval

3.8. Closure of the vaginal cuff

3.9. Final check and irrigation

3.10. Close-up patient
3.1.1. First incision and insert Veress or Hasson

3.1.2. Insufflate the abdomen

3.2.1. Insert first (optical) port

3.2.2. Insert laparoscope

3.2.3. Inspect abdomen (active bleeding, 360 look, operatability)

3.2.4. Insert second port under direct sight

3.2.5. Inspect and judge operatability/unexpected pathology)

3.2.6. Insert third port under direct sight

3.2.7. Insert fourth port under direct sight

3.3.1. Dissect adhesions to uterus/ovaria/intestine in pelvis

3.3.2. Mobilize intestine out of pelvis

3.4.1. Dissect ligaments and mobilize uterus

3.4.2. Skeletonized uterine arteries

3.4.3. Push off bladder

3.4.4. Identify location of ureters

3.5.1. Transect left uterine artery

3.5.2. Transect right uterine artery

3.5.3. Check color of uterus

3.5.4. Check if bladder and arteries are skeletonized enough

3.6.1. Colpotomy

3.6.2. Pneumoperitoneum is lost

3.7.1. Morcellated uterus

3.7.2. Extract uterus through vagina

3.8.1. Insert needle

3.8.2. Suture vaginal cuff

3.8.3. Extract needle

3.9.1. Check hemostasis

3.9.2. Check vaginal cuff stump

3.10.1. Remove instruments

3.10.2. Remove accessory operating ports (under direct sight)

3.10.3. Check access wounds/bleeding

3.10.4. Release $\mathrm{CO} 2$ from abdomen 
Table 1 continued

\begin{tabular}{ll}
\hline Surgical phases & Surgical steps \\
\hline & $\begin{array}{l}\text { 3.10.5. Remove laparoscope and first trocar port } \\
\text { 3.10.6. Suture port wounds } \\
\text { 3.10.7. Remove draping }\end{array}$ \\
& 4.1. Patient awake \\
4. Extubation & 4.2. Extubation \\
5. Postoperative & 5.1. Patient from OR table to ward bed \\
& 5.2. Sign-out procedure \\
& 5.3. Bring patient to recovery \\
6. Interoperative & 6.1. Cleaning of the OR \\
\hline
\end{tabular}

Table 2 Observed types of surgical flow disturbances

\begin{tabular}{ll}
\hline Equipment-/instrument-related & Setup device/connection \\
& Intraoperative repositioning \\
& Malfunctioning \\
Not present & Sterility \\
Environmental & Other/unclear \\
& Pager/telephone \\
Personnel-related & Door washing room \\
& Radio use \\
Procedure-related & Communication failure \\
& Irrelevant conversation \\
& Extra coagulation bleeding-site \\
& Unexpected adhesions \\
& Limited vision (condensation/smoke) \\
& Adverse event \\
& Conversion to laparotomy
\end{tabular}

\section{Results}

During the study period, $46 \mathrm{LHs}$ were performed in the conventional OR. Of those, 18 were not eligible (4 were not recorded because of no consent, 5 were excluded because of problems with the video recording, 6 due to audio problems and 3 for other reasons). In order to obtain the predefined 20 most recent procedures, first 8 procedures that were recorded were not observed. During construction of the operating room that was equipped with the observation system, $11 \mathrm{LHs}$ were performed in another integrated OR. Subsequently, in the observational integrated OR 27 LHs were performed until $20 \mathrm{LHs}$ that were registered were eligible
(3 were not recorded because of no consent, 2 were excluded because of technical problems and 2 for other reasons) (Fig. 2).

The overall observation duration of these 40 procedures was $103 \mathrm{~h}$ and $45 \mathrm{~min}$. Patient and procedure characteristics were similar between the two OR settings (Table 4). Only 3 minor complications were noted, all postoperatively (Table 5). Procedure time (conventional OR vs. integrated OR, minutes \pm standard deviation, mean $161 \pm 28$ vs. $150 \pm 34$ ) and operating time (skin to skin, mean $126 \pm 27$ vs. $116 \pm 31$ ) were not significantly different (NS) (Table 6).

In all six observations, both observers showed excellent agreement in their annotations (Cohen's kappa of .79-.98, 
Table 3 Effect of observed surgical flow disturbances (according to Persoon et al. [25])

1. Events with the potential to distract the sterile team

2. Sterile team member momentarily distracted: possible involvement of a single sterile member in an event not related to the primary task, e.g., a short head turn in response to a visual or auditory stimulus

3. Sterile team member engages in distraction: similar distraction in 2, but the sterile member engages with the source of distraction by verbally responding while maintaining primary task activity (multitasking)

4. Sterile team member's primary task interrupted: a single team member ceases his/her current tasks to engage entirely in the distracting stimulus

5. Sterile team momentarily distracted: two or more sterile team members respond to a stimulus with a short head turn, no verbal response

6. Sterile team engage in secondary tasks: two or more team members engage with the source of distraction by verbally responding while maintaining primary task activity

7. Sterile team's work interrupted—operation flow disrupted: interruption of the current primary task of the sterile team, the operation flow is disrupted

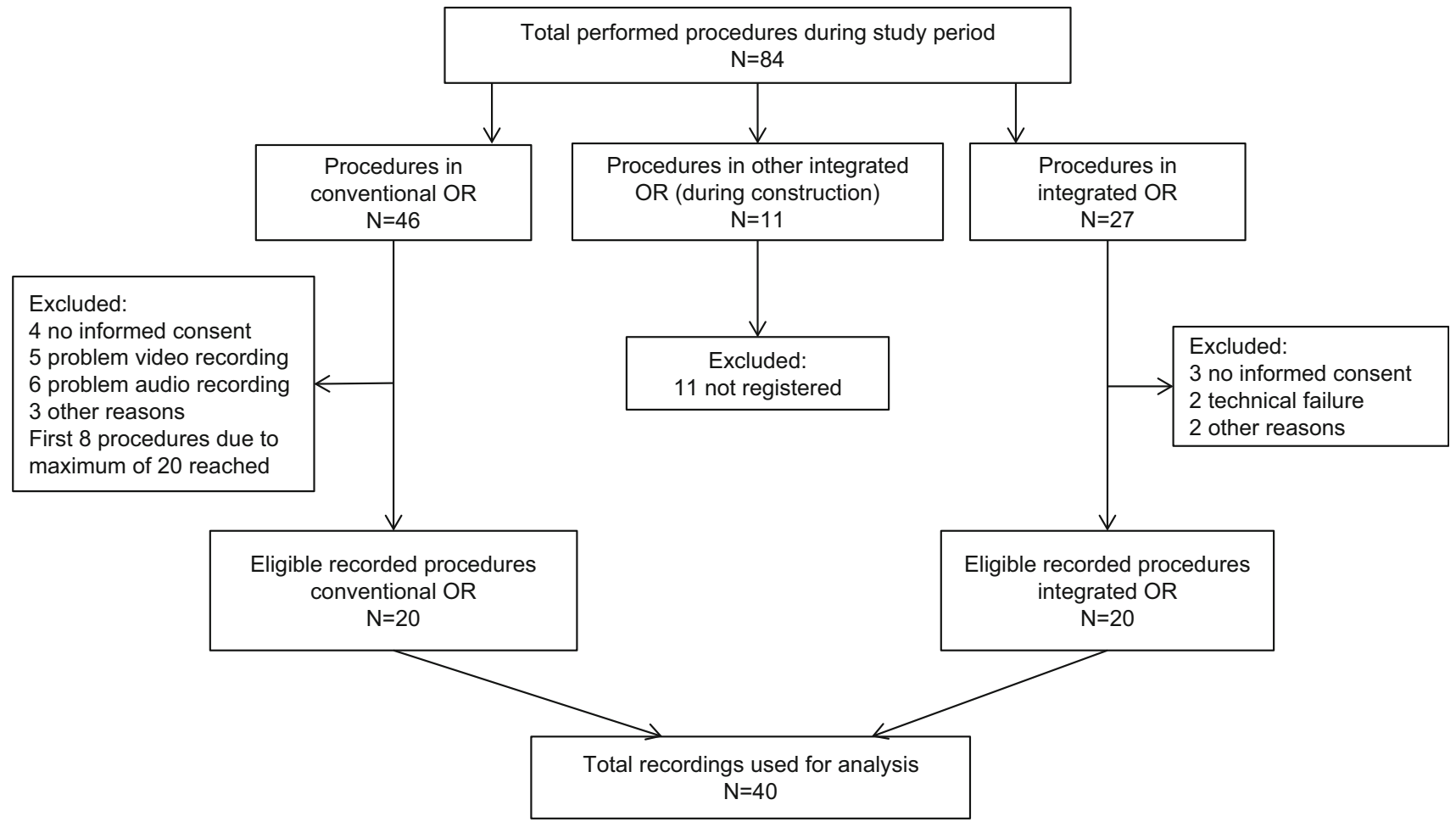

Fig. 2 Inclusion of eligible procedures

all observations combined $.85, p<.001)$. Therefore, the remaining procedures were annotated by the two observers separately (in total 36 observations by M.D.B. and 10 by S.R.C.D., respectively).

In total, during all 40 procedures, the researcher was present in the OR for $115 \mathrm{~min}(82 \mathrm{~min}$ in the conventional OR and $32 \mathrm{~min}$ in the integrated OR) [1.9\% of total observation time, mean $4 \mathrm{~min}$ per procedure, 0-12 (min$\max )]$. The mean effect on the sterile team members of this presence was 1.7 (see Table 3). The mean effect of noticed study awareness was 3.6 ( $N=52$ in 40 procedures).

\section{Incidence and effect of surgical flow disturbances}

A total of 1651 surgical flow disturbances were scored (mean \pm SD per procedure $40.8 \pm 19.4$ vs. $41.8 \pm 15.9$, NS) (unless otherwise specified, all comparisons are conventional vs. integrated OR). With regard to equipment, the mean number of surgical flow disturbances per procedure (setup of device, disturbance or problem regarding equipment, and intraoperative repositioning) was $6.3 \pm 3.7$ versus $8.5 \pm 4.0$, NS. More specifically, the mean duration of surgical flow disturbances regarding the setup of devices 
Table 4 Patient and procedure characteristics of analyzed LHs performed in the Bronovo Hospital, The Hague, between January 2011 and April 2012
Table 5 Adverse events all analyzed LHs. All adverse events did not require reoperation and occurred postoperatively

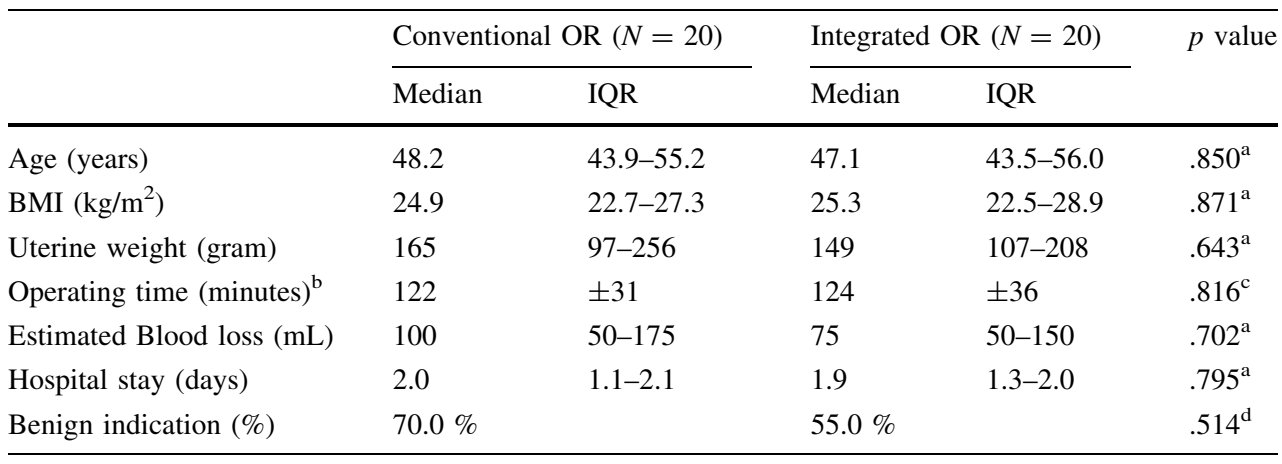

$I Q R$ Inter quartile range (25th and 75th percentile), BMI body mass index

a Mann-Whitney test

b Time according to medical file

c Mean \pm standard deviation and Student's $t$ test because of normal distribution

d Pearson's Chi-square

\begin{tabular}{llll}
\hline & Conventional OR $(N=20)$ & Integrated OR $(N=20)$ & Overall $(N=40)$ \\
\hline Infection & $1^{\mathrm{a}}(5.0 \%)$ & 0 & $1(2.5 \%)$ \\
Blood loss $>1 \mathrm{~L}$ & $0(0 \%)$ & $1^{\mathrm{b}}(5.0 \%)$ & $1(2.5 \%)$ \\
Others & $1^{\mathrm{c}}(5.0 \%)$ & 0 & $1(2.5 \%)$ \\
Total & $2(10.0 \%)$ & $1(5.0 \%)$ & $3(7.5 \%)$ \\
\hline
\end{tabular}

${ }^{a}$ Urinary tract infection

b Postoperative drop in hemoglobin. CT scan showed approximately $1500 \mathrm{cc}$ free fluid intraabdominally. Vital signs were stable, and after a blood transfusion with 2 packed cells, hemoglobin remained stable

${ }^{c}$ Patient suffered from sensibility loss in her right hand. The neurologist diagnosed a neuropraxia of the median nerve. Conservative management resulted in almost complete recovery

Table 6 Durations of all analyzed LHs (in minutes:seconds)

\begin{tabular}{|c|c|c|c|c|c|c|c|}
\hline \multirow[t]{3}{*}{ Observation duration } & \multicolumn{3}{|c|}{ Conventional OR $(N=20)$} & \multicolumn{3}{|c|}{ Integrated OR $(N=20)$} & \multirow{3}{*}{$\begin{array}{l}\text { Total }(N=40) \\
103 \mathrm{~h}: 45: 33 \\
p \text { value }^{\mathrm{c}}\end{array}$} \\
\hline & \multicolumn{3}{|c|}{$53 \mathrm{~h}: 42: 55$} & \multicolumn{3}{|c|}{$50 \mathrm{~h}: 02: 38$} & \\
\hline & Mean & $\pm \mathrm{SD}$ & Min-Max & Mean & $\pm \mathrm{SD}$ & Min-Max & \\
\hline Procedure time $^{\mathrm{a}}$ & 161:09 & $\pm 27: 38$ & $107: 37-210: 24$ & 150:08 & $\pm 34: 09$ & $98: 24-214: 52$ & .269 \\
\hline Operating time ${ }^{\mathrm{b}}$ & $126: 17$ & $\pm 26: 35$ & $66: 20-175: 44$ & $115: 42$ & $\pm 30: 38$ & $71: 48-174: 58$ & .251 \\
\hline
\end{tabular}

a Time between patient entering OR and leaving OR

b Time between first incision and last suture (skin to skin)

${ }^{c}$ Unpaired $t$ test calculated using http://www.graphpad.com/quickcalcs/ttest1/?Format=SD

$[N=16$ (total number of disturbances in 20 procedures), $1: 16 \pm 2: 05$ (mean $\pm \mathrm{SD}$ in minutes:seconds) vs. $N=27$, $1: 57 \pm 4: 32$, NS], disturbances or problems regarding equipment in general $(N=93,2: 19 \pm 3: 50$ vs. $N=110$, $1: 54 \pm 2: 19$, NS) and intraoperative repositioning $(N=16,0: 45 \pm 0: 37$ vs. $N=33,0: 39 \pm 0: 32$, NS) did not significantly differ either. Similarly, the mean effect of these disturbances did not show a clinically relevant difference (setup: $5.3 \pm 1.6$ vs. $4.2 \pm 2.0$, NS; disturbances regarding equipment in general: $5.8 \pm 1.7$ vs. $5.3 \pm 1.8, p=.04$; intraoperative repositioning: $4.6 \pm 1.9$ vs. $4.1 \pm 1.7, \mathrm{NS}$ ).

The number and total duration of the different devices and instruments accountable for these disturbances are shown in Table 7. Particularly, the difference between the conventional OR and the integrated OR with respect to 
disturbances caused by 'monitor' is notable $(N=10$, total duration $18 \mathrm{~min}$ vs. $N=46,87 \mathrm{~min}$; mean effect $4.7 \pm 2.2$ vs. $4.1 \pm 1.7$, NS). In the conventional OR one disturbance was caused by a failing connection of the second monitor (lasting $11 \mathrm{~min}$ ). In the integrated OR during four procedures there were problems with activating the third monitor (which was eventually found out to be caused by a hardware problem) (total duration $64 \mathrm{~min}$ ). The majority of the remaining duration of the surgical flow disturbances regarding the monitor in the integrated OR were caused by intraoperative repositioning $(N=28$, $18 \mathrm{~min}$, mean effect 4.1). A chronological representation per procedure is shown in Fig. 3.

The difference in total duration for surgical flow disturbances regarding 'instruments-dismountable' is caused by a variety of non-OR-related problems. No difference was found with regard to the number of surgical flow disturbances caused by devices that were not present in the OR $[N=12,2: 27 \pm 2: 00$ (mean $\pm \mathrm{SD}$ in minutes:seconds) vs. $N=16,3: 31 \pm 2: 37, \mathrm{NS}]$.

\section{Discussion}

The number of equipment-related surgical flow disturbances is not reduced by performing laparoscopic hysterectomy in an integrated OR instead of a conventional cart-based OR. Similarly, regarding the effect of these disturbances on the sterile team members, no clinically relevant difference between the two types of OR was found. Moreover, in the integrated OR, intraoperative repositioning of the monitors is a frequent and time-consuming source of disturbance.

It has been stated that optimizing the operating environment potentially may have a more significant impact on overall surgical outcome than improving individual surgical skill [29]. Although our study was not designed to detect differences in surgical outcome, we found that an integrated OR, as one of the most promising solutions to improve the operating environment, did not result in a reduction in equipment-related surgical flow disturbances. As a matter of fact, we even identified some potential hazards with the introduction of an integrated OR. The increased occupation that we observed with the repositioning of the monitors is important and has also been recognized by others [8]. Due to limitations in the degrees of freedom of the monitor and the ceiling-mounted boom arm, these disturbances were relatively time-consuming. Obviously, precise placement of the monitors can optimize the posture and improve ergonomics of all members of the surgical team [30]. However, apparently, the surgical team does not seem to be fully aware of the potential negative effect on the procedure during the repositioning. Having said this, the repositioning of the monitors fortunately did
Table 7 Devices and instruments accountable for surgical flow disturbances with respect to setup of device, disturbance or problem in general, and intraoperative repositioning

\begin{tabular}{|c|c|c|c|c|}
\hline \multirow[b]{2}{*}{ Surgical flow disturbance regarding } & \multicolumn{2}{|c|}{ Conventional OR $(N=20)$} & \multicolumn{2}{|c|}{ Integrated OR $(N=20)$} \\
\hline & $N$ & Total duration (h:min:sec) & $N$ & Total duration (h:min:sec) \\
\hline \multicolumn{5}{|l|}{ Devices } \\
\hline Diathermy & 27 & $00: 46: 36$ & 30 & 00:59:00 \\
\hline Endoscope & 2 & 00:01:00 & 3 & $00: 17: 11^{\mathrm{a}}$ \\
\hline Insufflator & 19 & $00: 21: 07$ & 21 & $00: 17: 34$ \\
\hline Irrigation suction & 7 & 00:09:15 & 9 & $00: 05: 44$ \\
\hline Light source & 3 & 00:00:50 & 4 & $00: 02: 24$ \\
\hline Morcellation device & 1 & $00: 03: 55$ & 4 & 00:04:54 \\
\hline Pedals & - & & 6 & 00:04:33 \\
\hline \multicolumn{5}{|l|}{ Instruments } \\
\hline Instruments_-dismountable & 25 & $01: 52: 38$ & 20 & $00: 45: 06^{\mathrm{b}}$ \\
\hline Instruments—non-dismountable & 11 & 00:19:04 & 13 & $00: 25: 34$ \\
\hline Trocar & 3 & 00:01:39 & 1 & 00:00:53 \\
\hline \multicolumn{5}{|l|}{ Devices-OR-related } \\
\hline Monitor & 10 & $00: 17: 52$ & 46 & $01: 26: 35^{\mathrm{c}}$ \\
\hline Overhead light & 3 & 00:00:52 & 2 & 00:00:49 \\
\hline Table & 6 & 00:05:05 & 7 & $00: 11: 18$ \\
\hline Tower & 11 & 00:09:16 & 6 & 00:05:14 \\
\hline
\end{tabular}

${ }^{a}$ Difference in total duration caused by one event lasting $16 \mathrm{~min}$

b Difference in total duration caused by a variety of non-OR-related problems

${ }^{c}$ Mean degree of influence $4.7 \pm 2.2$ versus $4.1 \pm 1.7, p=.37$ 
Fig. 3 Duration (minutes:seconds) of intraoperative repositioning of a monitor in the integrated OR (per procedure, chronological order)

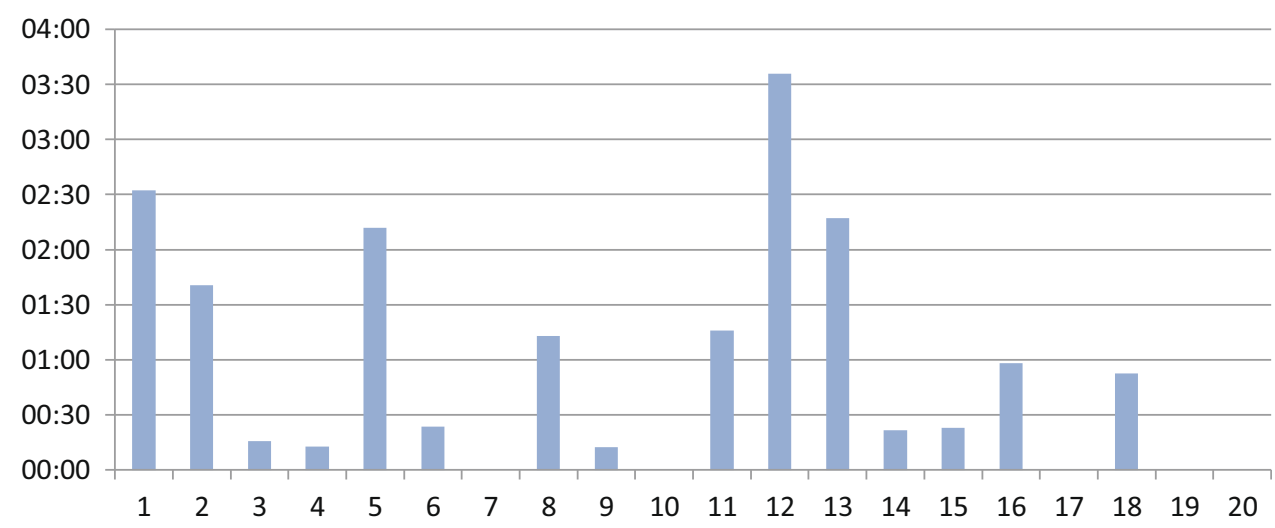

not have a direct effect on patient safety. However, what it does imply is that all implementations of either new technology, devices or instruments could potentially be hazardous in the chain of patient safety, because, especially during implementation of a new tool, one has to be aware that these are not always intuitive or straightforward in use [5]. Furthermore, the complete integration of the devices prevents easy (intraoperative) replacement in case of a dysfunctional device. Therefore, in an integrated OR, monitor positioning should be carefully planned and prepared preoperatively. This could be realized by the incorporating this as a mandatory item in a preoperative checklist $[5,31]$.

Previous research has demonstrated that surgical flow disturbances are directly related to surgical performance $[25,32,33]$. The number of surgical flow disturbances per procedure that we objectified was in line with similar studies. Persoon et al. [25] described surgical flow disturbances during endourological procedures (median operating time $35 \mathrm{~min}$ ) and found a median of 20 disturbances per procedure of which 1.7 were equipment related. Moreover, also the effect of these disturbances on the sterile team was similar to our results (4.97 vs. 4.1-5.8). Furthermore, Verdaasdonk et al. [8] observed problems with equipment during laparoscopic cholecystectomy. In 30 procedures, they identified 58 disturbances. Since laparoscopic cholecystectomy is usually performed in approximately an hour and in general is being considered as one of the lesser advanced procedures in surgery, this rate seems also comparable to the 6.3-8.5 equipment-related disturbances we found. Nevertheless, although it is known that laparoscopic surgery is prone to instrumentrelated disturbances [9], this number leaves substantial room for improvement, and apparently this needs to be realized by other solutions than performing minimal invasive surgery in an integrated OR instead of a conventional OR.

As recommended by others, taking care of a structured implementation process is a key factor for an innovation to become a success $[5,34,35]$. During the construction period, the complete OR team received multiple training sessions by the vendor to become familiar with the new OR setting. Despite this, and beside the repositioning-related disturbances caused by the monitor, we incidentally observed some struggling with the new equipment. This finding could be attributable to the learning curve. Regardless of training, in daily practice every new technique and technology comes along with a period a time during which one has to become completely familiar with the new environment. However, in our opinion, if the integrated OR really could reduce the number of surgical flow disturbances, that should-at least partially-be measurable from the first procedure performed in this OR, from both a patient safety and an ethical perspective. Moreover, observing 20 procedures in both types of OR should be sufficient to detect a clinically relevant difference, and graphical representations of our results did not show a learning curve (e.g., Fig. 3).

One of the strengths of our study was the use of video observation making rewinding and playing again possible, in order to make sure all disturbances and their consequences are accurately interpreted. As a consequence, also the presence and influence of the researcher during the procedure and the awareness of the OR team on the study was reduced to a minimum, thereby making the interference of the study with its own results (the Hawthorne effect) negligible.

Despite this strength for research purposes, video observation is also limited by both the very time-consuming analysis and legal aspects. These downsides still have to be overcome, before it can become common practice for research as well as training and legal purposes [8, 24, 36]. In our opinion, a more widespread adoption of video recording has an enormous potential to improve quality and safety of surgery. It could be used for general reviewing of the procedural steps, but mainly for the analysis of (near) failures and (team) training purposes, thereby taking quality improvement to the next level [37]. Finally, also 
patients were positive about the idea of having their procedures recorded [38].

The presence of equipment-related surgical flow disturbances remains multifactorial. The proclaimed reduction in these disturbances during MIS in an integrated OR could not be shown. Especially with respect to MIS, a dedicated training has been proven to result in increased safety, shorted operating time and less conversions [39]. Also a dedicated (nurse) team is beneficial to patient safety [40]. Furthermore, of all types of disturbances, equipment problems have among the highest influence on the surgical flow and procedures during which disruptions occur take longer. Therefore, it may be assumed that a well-trained and dedicated surgical team will be more beneficial to patient safety than changing the OR setting, i.e., performing MIS in an integrated OR instead of a conventional cartbased OR [4, 41, 42].

Nevertheless, the integrated OR does have already proven advantages that we did not take into account in our study. Most importantly, for all team members the ergonomics are more favorable, thereby reducing physical complaints and eventually dropout [30]. Furthermore, also time saving in the preoperative setup has been observed $[11,13,16]$. Therefore, performing MIS in an integrated OR could be regarded an ergonomically responsible innovation for those who are frequently performing advanced MIS.

In conclusion, compared to a conventional OR, performing MIS in an integrated OR does not seem to increase patient safety either by a reduction in the number of surgical flow disturbances or by a reduction in the effect of these disturbances on the members of the sterile team. In order to maintain the high level of surgical safety that has been established by laparoscopic surgery, the entire surgical team has to be fully aware that by performing surgery in an integrated OR different potential source for disruption arise.

Acknowledgments The authors want to acknowledge Arjan van Dijke for his extensive help with the video observation system.

\section{Compliance with ethical standards}

Disclosures Mathijs D. Blikkendaal, Sara R.C. Driessen, Sharon P. Rodrigues, Johann P.T. Rhemrev, Maddy J.G.H. Smeets, Jenny Dankelman, John J. van den Dobbelsteen and Frank Willem Jansen have no conflicts of interest or financial ties to disclose.

Open Access This article is distributed under the terms of the Creative Commons Attribution 4.0 International License (http://crea tivecommons.org/licenses/by/4.0/), which permits unrestricted use, distribution, and reproduction in any medium, provided you give appropriate credit to the original author(s) and the source, provide a link to the Creative Commons license, and indicate if changes were made.

\section{References}

1. Vincent C, Moorthy K, Sarker SK, Chang A, Darzi AW (2004) Systems approaches to surgical quality and safety: from concept to measurement. Ann Surg 239:475-482

2. Lingard L, Regehr G, Espin S, Whyte S (2006) A theory-based instrument to evaluate team communication in the operating room: balancing measurement authenticity and reliability. Qual Saf Health Care 15:422-426

3. Russ S, Arora S, Wharton R, Wheelock A, Hull L, Sharma E, Darzi A, Vincent C, Sevdalis N (2013) Measuring safety and efficiency in the operating room: development and validation of a metric for evaluating task execution in the operating room. J Am Coll Surg 216:472-481

4. Courdier S, Garbin O, Hummel M, Thoma V, Ball E, Favre R, Wattiez A (2009) Equipment failure: causes and consequences in endoscopic gynecologic surgery. J Minim Invasive Gynecol $16: 28-33$

5. Buzink SN, van Lier L, de Hingh IH, Jakimowicz JJ (2010) Risksensitive events during laparoscopic cholecystectomy: the influence of the integrated operating room and a preoperative checklist tool. Surg Endosc 24:1990-1995

6. Hu YY, Arriaga AF, Roth EM, Peyre SE, Corso KA, Swanson RS, Osteen RT, Schmitt P, Bader AM, Zinner MJ, Greenberg CC (2012) Protecting patients from an unsafe system: the etiology and recovery of intraoperative deviations in care. Ann Surg 256:203-210

7. Rodrigues SP, Wever AM, Dankelman J, Jansen FW (2012) Risk factors in patient safety: minimally invasive surgery versus conventional surgery. Surg Endosc 26:350-356

8. Verdaasdonk EG, Stassen LP, van der Elst M, Karsten TM, Dankelman J (2007) Problems with technical equipment during laparoscopic surgery. An observational study. Surg Endosc 21:275-279

9. Weerakkody RA, Cheshire NJ, Riga C, Lear R, Hamady MS, Moorthy K, Darzi AW, Vincent C, Bicknell CD (2013) Surgical technology and operating-room safety failures: a systematic review of quantitative studies. BMJ Qual Saf 22:710-718

10. Sevdalis N, Wong HW, Arora S, Nagpal K, Healey A, Hanna GB, Vincent CA (2012) Quantitative analysis of intraoperative communication in open and laparoscopic surgery. Surg Endosc 26:2931-2938

11. van Det MJ, Meijerink WJ, Hoff C, Pierie JP (2009) Interoperative efficiency in minimally invasive surgery suites. Surg Endosc 23:2332-2337

12. Herron DM, Gagner M, Kenyon TL, Swanstrom LL (2001) The minimally invasive surgical suite enters the 21 st century. A discussion of critical design elements. Surg Endosc 15:415-422

13. Kenyon TA, Urbach DR, Speer JB, Waterman-Hukari B, Foraker GF, Hansen PD, Swanstrom LL (2001) Dedicated minimally invasive surgery suites increase operating room efficiency. Surg Endosc 15:1140-1143

14. Samii A, Gerganov VM (2013) The dedicated endoscopic operating room. World Neurosurg 79:S15-S22

15. Lehoux P, Hivon M, Williams-Jones B, Miller FA, Urbach DR (2012) How do medical device manufacturers' websites frame the value of health innovation? An empirical ethics analysis of five Canadian innovations. Med Health Care Philos 15:61-77

16. Hsiao KC, Machaidze Z, Pattaras JG (2004) Time management in the operating room: an analysis of the dedicated minimally invasive surgery suite. JSLS 8:300-303

17. Nocco U, del Torchio S (2011) The integrated OR Efficiency and effectiveness evaluation after two years use, a pilot study. Int $\mathbf{J}$ Comput Assist Radiol Surg 6:175-186 
18. Stavroulis A, Cutner A, Liao LM (2013) Staff perceptions of the effects of an integrated laparoscopic theatre environment on teamwork. Gynecol Surg 10:177-180

19. Cutner A, Stavroulis A, Zolfaghari N (2013) Risk assessment of the ergonomic aspects of laparoscopic theatre. Gynecol Surg 10:99-102

20. National Transportation Safety Board Aircraft Accident Report. Northwest Airlines, Inc. McDonnell Douglas DC-9-82, August 16, 1987, NTSB/AAR-88/05. 1988. 10-12-2014

21. National Transportation Safety Board Aircraft Accident Report. Eastern Airlines, Inc. L-1011, December 29, 1972, NTSB/AAR73/14. 1973. 10-12-2014

22. Hu YY, Arriaga AF, Peyre SE, Corso KA, Roth EM, Greenberg CC (2012) Deconstructing intraoperative communication failures. J Surg Res 177:37-42

23. Zheng B, Martinec DV, Cassera MA, Swanstrom LL (2008) A quantitative study of disruption in the operating room during laparoscopic antireflux surgery. Surg Endosc 22:2171-2177

24. Guerlain S, Adams RB, Turrentine FB, Shin T, Guo H, Collins SR, Calland JF (2005) Assessing team performance in the operating room: development and use of a "black-box" recorder and other tools for the intraoperative environment. J Am Coll Surg 200:29-37

25. Persoon MC, Broos HJ, Witjes JA, Hendrikx AJ, Scherpbier AJ (2011) The effect of distractions in the operating room during endourological procedures. Surg Endosc 25:437-443

26. den Boer KT, Dankelman J, Gouma DJ, Stassen HG (2002) Peroperative analysis of the surgical procedure. Surg Endosc 16:492-499

27. Tremblay C, Grantcharov T, Urquia ML, Satkunaratnam A (2014) Assessment tool for total laparoscopic hysterectomy: a Delphi consensus survey among international experts. J Obstet Gynaecol Can 36:1014-1023

28. Healey AN, Primus CP, Koutantji M (2007) Quantifying distraction and interruption in urological surgery. Qual Saf Health Care 16:135-139

29. Wong SW, Smith R, Crowe P (2010) Optimizing the operating theatre environment. ANZ J Surg 80:917-924

30. van Det MJ, Meijerink WJ, Hoff C, van Veelen MA, Pierie JP (2008) Ergonomic assessment of neck posture in the minimally invasive surgery suite during laparoscopic cholecystectomy. Surg Endosc 22:2421-2427

31. Verdaasdonk EG, Stassen LP, Hoffmann WF, van der Elst M, Dankelman J (2008) Can a structured checklist prevent problems with laparoscopic equipment? Surg Endosc 22:2238-2243

32. Hsu KE, Man FY, Gizicki RA, Feldman LS, Fried GM (2008) Experienced surgeons can do more than one thing at a time: effect of distraction on performance of a simple laparoscopic and cognitive task by experienced and novice surgeons. Surg Endosc 22:196-201

33. Pluyter JR, Buzink SN, Rutkowski AF, Jakimowicz JJ (2010) Do absorption and realistic distraction influence performance of component task surgical procedure? Surg Endosc 24:902-907

34. Lingard L, Regehr G, Orser B, Reznick R, Baker GR, Doran D, Espin S, Bohnen J, Whyte S (2008) Evaluation of a preoperative checklist and team briefing among surgeons, nurses, and anesthesiologists to reduce failures in communication. Arch Surg 143:12-17

35. Norton E (2007) Implementing the universal protocol hospitalwide. AORN J 85:1187-1197

36. Rockstroh M, Franke S, Neumuth T (2014) Requirements for the structured recording of surgical device data in the digital operating room. Int J Comput Assist Radiol Surg 9:49-57

37. Makary MA (2013) The power of video recording: taking quality to the next level. JAMA 309:1591-1592

38. Raghavendra M, Rex DK (2010) Patient interest in video recording of colonoscopy: a survey. World J Gastroenterol 16:458-461

39. Glasgow RE, Adamson KA, Mulvihill SJ (2004) The benefits of a dedicated minimally invasive surgery program to academic general surgery practice. J Gastrointest Surg 8:869-873

40. Kenyon TA, Lenker MP, Bax TW, Swanstrom LL (1997) Cost and benefit of the trained laparoscopic team. A comparative study of a designated nursing team vs a nontrained team. Surg Endosc $11: 812-814$

41. Antoniadis S, Passauer-Baierl S, Baschnegger H, Weigl M (2014) Identification and interference of intraoperative distractions and interruptions in operating rooms. J Surg Res 188:21-29

42. Al-Hakim L, Sevdalis N, Arora S (2012) On surgical disruption: rating, expected operative time or actual wasted time-some comments on Gillepsie et al (2012). BMJ Qual Saf 21:532 